\title{
A construção da consciência socioambiental no ensino de Geografia
}

\author{
The construction of socio-environmental awareness in Geography teaching
}

\author{
Philipe de Freitas Sek ${ }^{1}$, Edson Soares Fialho ${ }^{2}$
}

\begin{abstract}
RESUMO: O Programa Institucional de Bolsa de Iniciação à Docência (PIBID) para a formação docente de qualidade, é no presente trabalho o foco da reflexão sobreo ensino de Geografia, a partir da experiência sobre o papel capaz de viver os possíveis dramas e alegrias da prática docente, e também sobre a oportunidade de elaboração e aplicação do projeto "Consciência Socioambiental: uma proposta para o ensino de Geografia" desenvolvido por discentes do curso de Geografia da Universidade Federal de Viçosa (UFV), na Escola Estadual Dr. Mariano da Rocha, no município de Teixeiras-MG, que tem como pano de fundo os preceitos geossistêmicos que apontam para uma compreensão da totalidade do mundo, na esperança de contribuir para a Educação Ambiental com um olhar geográfico (comumente abordada no Ensino Básico pelas disciplinas de Geografia e Ciências/Biologia).
\end{abstract}

PALAVRAS-CHAVE:PIBID; Paisagem; Meio ambiente e Geografia.

\begin{abstract}
The Institutional Program of Scholarship Initiation to Teaching (PIBID) for quality teacher training, is in the present work the focus of reflection on the teaching of Geography, from the experience on the role able to live the possible dramas and joys of teaching practice, and also on the opportunity to develop and apply the project "Socio-environmental Consciousness: a proposal for the teaching of Geography developed by students of the Geography course of the Federal University of Viçosa (UFV), in the State School Dr. Mariano Rocha in the Town of Teixeiras-MG, which has as background the geosystemic precepts that point to an understanding of the totality of the world, hoping to contribute to Environmental Education with a geographic look (commonly addressed in primary schools by the disciplines of Geography and Science / Biology).
\end{abstract}

KEYWORDS: PIBID; Landscape; Environment and Geography.

\section{INTRODUÇÃO}

${ }^{1}$ Professor, Licenciado na Universidade Federal de Viçosa (UFV). Av. P. H. Rolfs, s/n. Campus Universitário. ViçosaMG. CEP: 36570-900; Viçosa (MG), Brasil, E-mail: philipe.sek@ufv.br. https://orcid.org/0000-0003-3334-1082

${ }^{2}$ Professor Associado III do curso de Geografia e no Programa de Pós-graduação em Geografia da Universidade Federal de Viçosa (UFV). Coordenador do PIBD de Geografia. Av. P. H. Rolfs, s/n. Campus Universitário. Viçosa-MG. CEP: 36570-900.e-mail: fialho@ufv.br. https://orcid.org/0000-0002-1162-632X

Agradecimentos ao Programa Institucional de Bolsa de Iniciação à Docência (PIBID), que possibilitou a vivência da docência no meio escolar, bem como ao Laboratório de Biogeografia e Climatologia (Bioclima) do Departamento de Geografia da UFV. 
O Programa Institucional de Bolsa de Iniciação à Docência (PIBID) é financiado pela Coordenadoria de Aperfeiçoamento de Pessoal de Nível Superior (CAPES) e ligado ao Ministério da Educação (MEC). É uma importante política pública de valorização dos cursos de licenciatura no Brasil, que direciona esforços a uma formação docente de qualidade, capaz de vivenciar a prática escolar com todos os seus desafios e tensões. Por meio dele, Instituições de Ensino Superior (IES) têm a possibilidade de estreitar suas relações para com as escolas do Ensino Básico, seu maior objetivo e campo de atuação. Possibilita, assim, uma troca de conhecimentos entre ambas as esferas a fim de se obter o constante renovar dos professores envolvidos e também o crescimento pessoal e profissional dos bolsistas.

Cabe salientar que formar-se professor não deve ser encarado como uma tarefa simplória, visto que ela é complexa, a partir do momento que lidamos com pessoas de diversos pensamentos, ideologias, costumes, realidades extraescolares e etc. Ao mesmo tempo, ser professor não se constitui enquanto um dom, conforme Luciano et al (2013), isto porque, todo o estudo e tempo depreendidos, aprendendo com os erros e acertos, com as observações e, acima de tudo, com a busca de novas práticas capazes de se alcançar algum tipo de objetivo previamente estabelecido. De acordo com Nóvoa (2009):

[...] ser professor é compreender os sentidos da instituição escolar, integrar-se numa profissão, aprender com os colegas mais experientes. É na escola e no diálogo com os outros professores que se aprende a profissão. $\mathrm{O}$ registro das práticas, a reflexão sobre o trabalho e o exercício da avaliação são elementos centrais para o aperfeiçoamento e a inovação. São estas rotinas que fazem avançar a profissão [...] (NÓVOA, 2009, p. 12).

Sendo assim, o planejamento prévio é outra característica proporcionada pelo programa e que deve ser mantida e incentivada. Pensar nas possíveis potencialidades ou mesmo falhas e contrastar com a realidade apresentada é uma maneira de desenvolver habilidades e conhecimentos próprios do ramo.

O PIBID, enquanto programa, talvez seja o que cumpra o exercício dos três pilares da Universidade moderna: Ensino, Pesquisa e Extensão de maneira articulada, dada a liberdade que cada coordenador possui de direcionar seu grupo de bolsistas, seja por meio da leitura de textos e a posterior discussão durante os encontros, seja pelo desenvolvimento de oficinas e palestras junto aos estudantes da escola pública ou, ainda, pela pesquisa e elaboração de projetos de ensino para o seu público alvo e etc. A iniciação às práticas docentes é o foco principal.

Ademais, o PIBID é um aliado dos estágios supervisionados, obrigatórios a cada curso. Segundo Silveira (2015, p. 363), “a iniciação à docência, praticada no PIBID, não é uma reprodução do estágio", que em sua maioria possui um perfil muito bem definido dentro dos cursos de 
licenciatura, como nos mostram Anjos e Costa (2012), neste caso, para a realidade do curso de Pedagogia:

[...] a história dos cursos de licenciatura, inclusive o curso de Pedagogia nos mostra uma concentração de conteúdos teóricos no início do curso e deixam geralmente para o final as ações práticas. Ações por meio de estágio quase sempre fragmentados, com o intuito de colocar em prática os conhecimentos obtidos no curso [...]. (ANJOS e COSTA, 2012, p. 1).

Este aliado é valioso à formação por promover a diluição da prática escolar ao longo do curso e, em muitos dos casos por ser o primeiro contato do licenciando com a realidade, antes mesmo dos estágios. O contato precisa ser bem orientado, pois, por mais que saibamos exatamente aquilo que nos espera dentro da sala de aula (pelo menos no campo das ideias e naquilo que é considerado senso comum), o primeiro momento pode e acaba por assustar o estudante sem o devido preparo teórico e apoio de um docente já com experiência em desmistificar certos tipos de primeiras impressões, tais como: indisciplina, conflito, indiferença e provocações.

É importante reconhecer que os estágios obrigatórios e o PIBID são atividades separadas que se complementam, conforme Noffs e Rodrigues (2016) apontam. O primeiro tem por objetivo articular a teoria até o momento apreendida junto às horas de observações e intervenções pontuais, enquanto que o segundo, dotado de maior liberdade em observar, analisar e atuar sobre a realidade, busca o desenvolvimento de uma consciência otimista do "ser professor" e sua função social. Nada impede que ambas as práticas se complementem.

O PIBID, nessa perspectiva, se configura como elemento integrador entre teoria e prática na formação dos futuros professores, uma vez que pode proporcionar articulação entre os conhecimentos adquiridos na universidade aos saberes observados no contexto da escola de educação básica. Desse modo, Noffs (2013) reafirma a importância do caráter da pesquisa como processo fundamental da formação docente, contribuindo para a formação de professores que na problematização das práticas possam vir a refletir sobre sua ação, auxiliando na superação à visão técnica na qual os problemas se reduzem a cumprir metas do programa.

Enquanto, o estágio é identificado por Pimenta (2012) como uma prática sob a supervisão de um profissional que conheça e saiba lidar com as situações do cotidiano escolar. Apresenta-se como uma atividade a ser realizada durante o curso de formação junto ao campo de atuação profissional, possibilitando aos alunos a inserção nos contextos de intervenção docente.

O PIBID-Geografia da Universidade Federal de Viçosa (UFV), atuou por meio de um projeto, que buscou compreender a relação entre a sociedade e a natureza, por meio de uma perspectiva transdisciplinar, conforme Fialho (2007 e 2008). O título do projeto PIBID de Geografia desenvolvido 
se intitulava: "Geosociobiodiversidade: as impressões (in) visíveis da ação humana sobre a paisagem", foi desenvolvido em duas escolas.

A primeira em Viçosa, na Escola Estadual Effie Rolfs e a segunda em Teixeiras, na Escola Estadual Dr. Mariano da Rocha, onde foi aplicado o subprojeto: "Consciência Socioambiental: uma proposta para o Ensino de Geografia" na escola de Ensino Básico, cujo objetivo do mesmo foi despertar a consciência ambiental, bem como produzir reflexões dos discentes, frente ao atual contexto de apropriação da natureza intensivo e inadequado, o que produz sérios impactos à saúde e a piora da qualidade de vida.

\section{MATERIAIS E MÉTODOS}

Apesar de um caráter ambientalista, transpassado logo no título, o subprojeto em questão teve como premissa trabalhar a Geografia na articulação os aspectos físico-ambientais e humanos, "pois acredita-se que sua maior riqueza está nessa característica” (MENDONÇA, 2001, p. 115), e elege para tal feito o conceito de "Paisagem" e "é preciso frisar bem que não se trata somente da paisagem 'natural' mas da paisagem total integrando todas as implicações da ação antrópica" (BERTRAND, 2004, p. 141), basilar para esta ciência moderna e com um potencial único de união entre ambas as facetas do espaço (física e humana).

O entendimento desta interação sociedade/natureza ou das temáticas físicas e ambientais já na Educação Básica é vital para a formação do cidadão reflexivo e que compreende as relações de seu lugar (FIALHO, 2011). Embora o caráter ambiental seja evidente, o projeto também abre margem para outras discussões, dada a sua amplitude e diversidade de integrantes.

Considerado a Base Nacional Comum Curricular (BNCC), enquanto um tema transversal e interdisciplinar, ou seja, aquele que deve perpassar por conhecimentos e pontos de vista de diversas áreas do saber, o meio ambiente ou a Educação Ambiental propriamente dita encontra campo fértil e atual para sua discussão, tendo em vista a crescente divulgação de notícias referentes ao tema e a facilidade de acesso às mesmas.

Durante a atuação no PIBID, trabalhos em projetos próprios previamente elaborados foram incentivados a serem desenvolvidos, mas sempre, com a preocupação em buscar um embasamento teórico, escolha de metodologia adequada, bem como, a avaliação e descrição das atividades a serem executadas na escola de Ensino Básico, neste caso, na Escola Estadual Dr. Mariano da Rocha localizada em Teixeiras-MG (Figura 1). 
Figura 1: Localização da Escola Estadual Dr. Mariano da Rocha (Teixeiras-MG).

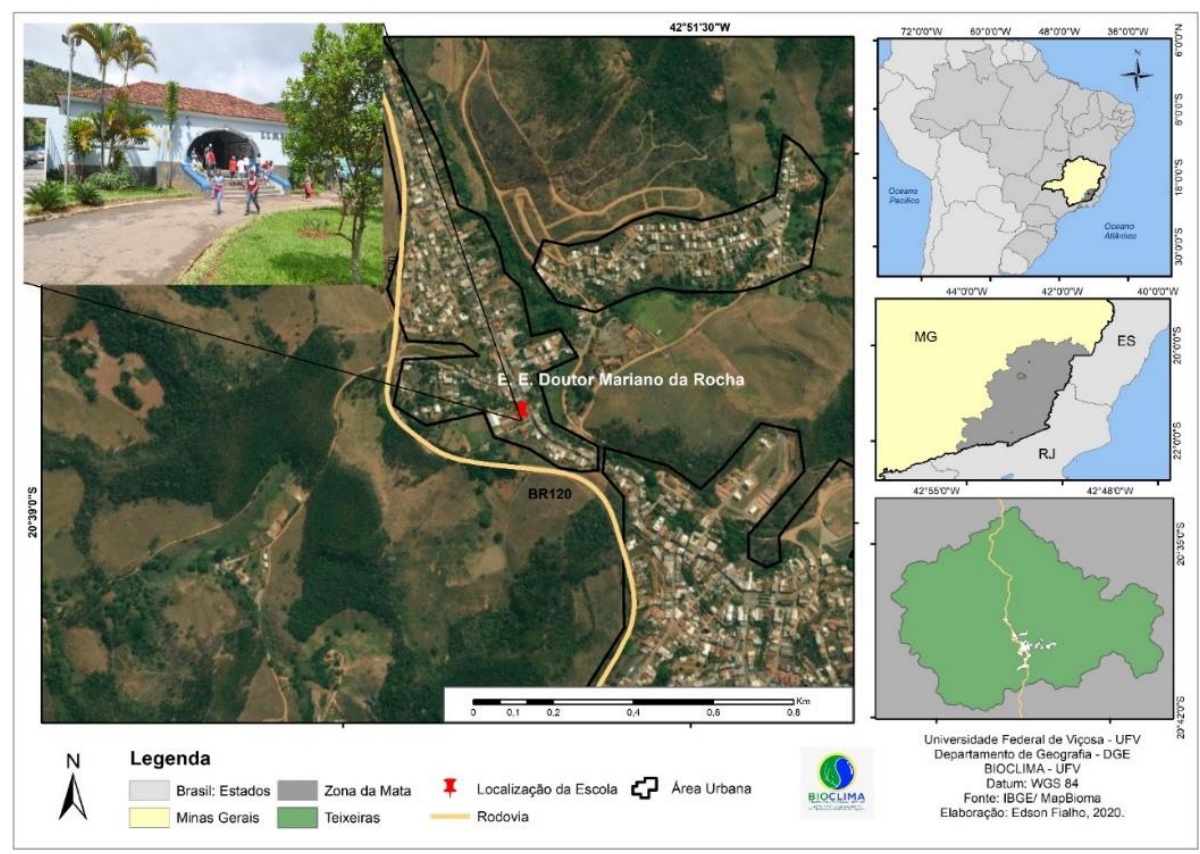

Dentre as propostas de trabalho em classe desenvolvidas pelos pibidianos, o projeto de Consciência ambiental, baseado em uma perspectiva geossistêmica no contexto da paisagem, permitiu desenvolver uma maior organização e uma sequência didática, capaz de favorecer o entendimento e aprendizado dos discentes envolvidos.

Sendo assim, as páginas que se seguem refletem sobre esta experiência de projeto de ensino, sua formulação, aplicação e contribuição ao crescimento enquanto estudante de licenciatura.

Buscando compreender sobre os conceitos que norteiam a discussão ambiental, por exemplo, natureza, meio ambiente e em como eles vêm sendo tratados na ciência geográfica desde a sua sistematização, em meados do século XIX, até os dias atuais. A fase de embasamento teórico foi importe para o discernimento do objetivo do projeto.

Em “Os (des) caminhos do meio ambiente" (1990), um dos principais tópicos abordados pelo professor Carlos Walter Porto Gonçalves consiste em como o conceito de "natureza", atualmente vigente em nossa sociedade, sofreu, ao longo dos séculos, uma separação do "homem" através de alguns marcos históricos, como: a instauração do Cristianismo ou mesmo o emprego do método científico cartesiano, dentre outros. Para este mesmo autor:

[...] a ideia de natureza objetiva e exterior ao homem, o que pressupõe uma ideia de homem não natural e fora da natureza, cristaliza-se com a civilização industrial inaugurada pelo capitalismo. As ciências da natureza se separam das ciências do homem; cria-se um abismo colossal entre uma e outra e, como veremos mais adiante, tudo isso não é só uma questão de concepção de mundo [...]. (PORTOGONÇALVES, 1990, p. 35): 
Em seguida, aproximando um pouco mais a discussão da Geografia, o livro "Geografia e meio ambiente" (2014), do professor Francisco Mendonça, revela em dois momentos distintos a maneira com que o tema é tratado pela ciência. O primeiro momento é de cunho naturalista, privilegiando a descrição das características naturais da Terra e de seus diferentes espaços, que vai desde o século XIX até meados das décadas de 1960 do século passado, quando, de acordo com Mendonça (2014):

[...] as descrições feitas por geógrafos deste período pautaram-se pelo detalhamento das características físicas dos lugares, mensurando catalogando-as, ao mesmo tempo que procurando explicações para suas dinâmicas e o estabelecimento de leis numa tentativa de sistematização dos conhecimentos apreendidos [...]. (MENDONÇA, 2014, p. 22).

E um segundo momento, quando a natureza passa a ser interpretada a partir de suas experiências relacionais com a sociedade. A descrição pura deixa de ser o foco e as relações entre as partes ganham destaque, momento que se estende das décadas de 1970 até os dias atuais. Ainda de acordo com Mendonça (2014):

[...] o desenvolvimento, no Brasil, do tratamento da temática ambiental dentro da geografia e segundo uma concepção que inter-relaciona sociedade e natureza, foi algo que se deu muito lentamente durante as décadas de 1970 e 1980, em função do que se poderia desejar, principalmente quando se observa que tal desenvolvimento se deu única e exclusivamente dentro da geografia física [...]. (MENDONÇCA, 2014, p. 64).

Antes mesmo de apresentar o terceiro e último texto que serviu de base para a composição da ideia principal do projeto, uma observação acerca dos dois primeiros se faz necessária. Ambos os textos fazem referência ao surgimento do movimento social ecológico por volta das décadas de 1960 e 1970 no mundo e, posteriormente, no Brasil. Entendendo o movimento social, independente de qual seja, como uma manifestação organizada de que a sociedade, como um todo ou ao menos parte dela, encontra-se em total desacordo com a ordem.

O caso do movimento ecológico, a forma desarmônica com que o ser humano veio se apropriando de seu meio é pertinente ressaltar que há uma congruência entre as datas de surgimento do movimento com o início do segundo momento na história do pensamento geográfico referente ao trato das questões ambientais.

Tendo em vista que a Geografia começa a ganhar forma em meados dos anos 1970, conhecida como Geografia Crítica ou Radical, possui um cunho social e de entendimento dos reais problemas da sociedade, muito fortes, quando comparados aos demais paradigmas que a antecederam, é natural que seja levantada a hipótese de que, para aquele momento em específico a Geografia enquanto 
ciência, tenha ouvido o clamor da sociedade e incorporado nas discussões de seu objeto de estudo (para o caso ambiental), as relações com o ser humano.

Obviamente, definir datas específicas para este tipo de análise torna-se impossível, pois tratase aqui de uma análise referente a um processo que é dinâmico, entretanto o encadeamento das ideias e a cronologia com que elas são apresentadas são inegáveis.

Retomando à apresentação inicial, o artigo intitulado "Geografia Socioambiental” (2001), também elaborado pelo professor Francisco Mendonça, além de fazer alguns apontamentos sobre o que vem a ser o conceito de "meio ambiente" no meio científico, "na evolução do conceito de meio ambiente (environment, environnement) observa-se o envolvimento crescente das atividades humanas, sobretudo nas quatro últimas décadas" (MENDONÇA, 2001, p. 116). Também analisa e identifica um novo paradigma à Geografia, assim como os já conhecidos: Tradicional ou Clássico, Teorético Quantitativo, Crítico ou Radical e etc. Nesta corrente, que dá nome ao artigo (Geografia Socioambiental), "a problemática ambiental na Geografia deixa de ser identificada apenas como ligada à Geografia física e passa a ser geográfica” (MENDONÇA, 2001, p. 122). Mendonça (2001) demonstra que:

[...] observa-se assim na atualidade, diante de tão importante desafio, uma forte tendência à utilização, de forma ampla, do termo socioambiental, pois tornou-se muito difícil e insuficiente falar de meio ambiente somente do ponto de vista da natureza quando se pensa na problemática interação sociedade-natureza do presente, sobretudo no que concerne a países em estágio de desenvolvimento complexo. O termo "sócio" aparece, então, atrelado ao termo "ambiental" para enfatizar o necessário envolvimento da sociedade enquanto sujeito, elemento, parte fundamental dos processos relativos à problemática ambiental contemporânea [...]. (MENDONÇA, 2011, p. 117).

Em suma, é possível traçar aqui a transformação da "natureza" em "meio ambiente", inicialmente empregados como sinônimos e posteriormente dissociados por conta do acréscimo das relações sociais. Entretanto, críticas acerca do conceito (meio ambiente) foram e continuam a ser estabelecidas devido à sua imprecisão e polissemia.

Para Geraldine (2014, p. 207), “dentre as várias considerações possíveis, o conjunto das críticas desses importantes geógrafos incide praticamente numa mesma tecla, a saber: a falta epistemológica em que o conceito meio ambiente vem se enquadrando no discurso geográfico". Através de rápidas observações na escola, e de maneira mais específica dentro da sala de aula, quando são tratadas as temáticas ambientais, fica claro que ambos os termos (natureza e meio ambiente) ainda são tratados como sinônimos, confirmando parte da frase citada pelo especialista em educação Mozart Neves Ramos. Segundo ele, "temos uma Escola do século XIX, um Professor do século XX e um Aluno do século XXI". Enquanto tais disparidades não forem reduzidas, seja para as questões ambientais ou 
para qualquer outro tipo de temática contemplada pelo ensino, este choque entre as gerações continuará prejudicando o sistema educacional como um todo.

Desta maneira, estão lançadas as bases necessárias ao delineamento do objetivo central. Compreendendo a educação enquanto uma ferramenta dotada de intencionalidade, porquê não trabalhar justamente no sentido contrário ao estabelecido? À separação homem/meio? Para Callai (2001, p. 143), este “é um tipo de educação que deve mostrar que é possível desafiar o que está estabelecido, exercitar a crítica, discutir os encaminhamentos, em vez de simplesmente aceitar. Porém, para isso, é preciso conhecer, ter informações, saber organizá-las."

\section{GEOSSISTEMA: AUTORES, INFLUÊNCIAS E APLICAÇÕES NO PROJETO}

Ainda durante a fase de embasamento teórico, alguns termos surgiram com demasiada frequência quando comparados aos demais. É o caso das palavras "holístico" na Geografia. Segundo o dicionário Aurélio (2001), holístico é o "que dá preferência ao todo ou a um sistema completo e não à análise, à separação das respectivas partes componentes", e holismo é a "teoria de que existe uma tendência à interação dos elementos do universo e em especial dos seres vivos, e não de uma soma dessas partes". Termos estes adequados à tentativa de união entre natureza e sociedade aqui proposta.

No campo das ciências em geral, estes pressupostos têm o seu início na Biologia com Ludwig Von Bertalanffy (1901-1972), com a sua Teoria Geral dos Sistemas que, segundo Reis Júnior e Perez Filho (2006, p. 2), "é quando o holismo depura-se em algo mais formalizado", capaz de influenciar diversos outros seguimentos, assim como a própria Geografia. Dentro desta, são dois os principais expoentes daquilo que passa a ser conhecido como Geossistema. Victor B. Sotchava (1905-1978), atribuiu-se a utilização do termo pela primeira vez e ao francês Georges Bertrand, conhecido pela hierarquização destes sistemas na paisagem. No Brasil, Carlos Augusto de Figueiredo Monteiro (2001) é tido como referência no assunto.

Entretanto, assim como o conceito de "meio ambiente", a ideia de geossistema não parece apontar uma clareza muito bem definida quanto à sua formulação conceitual, como nos mostra Suertegaray (2008 apud REHBEIN, 2010), "há controvérsias em relação ao conceito de geossistema, ora compreendido como sistema natural, ora concebido como sistema integrativo da natureza com a sociedade". Desta maneira, tornou-se possível identificar três tipos de funções diferentes ao termo, são elas: geossistema enquanto método de análise da paisagem, que segundo Monteiro (2001):

[...] prevê quatro etapas, a saber: a análise (levantamento das variáveis naturais e antrópicas), a integração (fusão dos recursos e dos usos, levando em conta 
problemas diagnosticados), a síntese (cumprimento desta fusão, inferindo unidades homogêneas) e a aplicação (elucidação quanto ao estado do ambiente [...].(MONTEIRO, 2001, p. 53).

Em seguida o geossistema, enquanto estrato que compõe a hierarquia da paisagem, sistema de classificação que "comporta seis níveis temporo-espaciais; de uma parte, a zona, o domínio e a região; de outra parte, o geossistema, o geofácies e o geótopo" (BERTRAND, 2004, p. 144), constitui assim, "uma boa base para os estudos de organização do espaço porque ele é compatível com a escala humana" (BERTRAND, 2004, p. 146). E, por último, o geossistema enquanto adjetivo, que de acordo com Reis Júnior e Perez Filho (2006):

[...] tem por geossistêmica (a nosso ver, adjetivo devendo denotar que se enxergou a unidade dos fenômenos da natureza e da sociedade), uma abordagem que, na verdade, apenas sugere conexão e implicações; abordagem que é holística sim, mas "geo-sistêmica" [...]. (REIS JÚNIOR e PEREZ FILHO, 2006, p. 2).

Portanto, ao compreender que trabalhar questões metodológicas ou de hierarquia da paisagem com estudantes do Ensino Básico é uma tarefa complexa e desnecessária ao que se propõe o ensino em questão ou mesmo o projeto, optou-se por considerar o geossistema enquanto um adjetivo e priorizar as relações ou, como a própria definição de "holismo" sugere, "a tendência à interação dos elementos".

A princípio, na tentativa de materializar o objetivo e método até agora descritos dentro da sala de aula, dividiu-se a "paisagem" dos envolvidos de acordo com seus elementos formadores: rocha, solo, relevo, vegetação e clima, destinando para cada um deles uma exposição teórica atrelada a algum exercício prático por definir, além de preparar uma introdução à Geografia e às atividades em questão e, por último, uma finalização adequada, capaz de entrelaçar todos os elementos abordados ao elemento "homem", totalizando sete encontros com os estudantes escolhidos para aplicação.

\section{CONDUÇÃO E DESCRIÇÃO DAS ATIVIDADES}

O ensino que vigora é pautado pela divisão disciplinar dos conteúdos, ou seja, a organização do conhecimento em blocos por afinidade/proximidade, constituindo assim as "matérias". Dentro desta organização, mais uma vez o ideal disciplinar toma forma e se manifesta nos livros didáticos organizados em capítulos, normalmente cada tópico corresponde a um capítulo, que juntos compõem a "matéria". Todavia, segundo Kanashiro (2008, p. 14) identifica uma diversidade de concepções e usos do livro, que pode ser utilizado como único suporte na organização da aula. Para outros, o mesmo é uma ferramenta auxiliar das tarefas cotidianas, como também existem aqueles, que entendem o livro 
como um obstáculo ao desenvolvimento das capacidades e habilidades dos alunos, pois simplifica, na medida em que, oferece um conhecimento pronto.

Já foi comentada, no item um deste texto, a oportunidade de planejamento e aprendizado com os erros, proporcionados pelo PIBID. Felizmente, após a aplicação dos dois primeiros encontros, em duas turmas de primeiro ano do Ensino Médio (Figura 2), percebemos o quão influenciados pela característica disciplinar do ensino, há pouco mencionada, nós estávamos, o que viria a dificultar o entrelaçamento das ideias e do elemento "homem" no sétimo e último encontro até então previsto. Desta maneira, o planejamento inicial das atividades caminhava em sentido totalmente oposto à proposta de método "geossistêmico" aqui delineada, totalmente contrária ao holismo pretendido.

A partir de então, alterou-se toda a estrutura das atividades pretendidas, o que eram sete encontros transformaram-se em quatro, sem descartar os dois primeiros já ministrados. O elemento "homem" passa a ser considerado em todos os encontros e eles, por sua vez, organizam-se em grupos de conteúdos relacionados entre si, conforme a sequência didática elaborada e apresentada a seguir.

Figura 2: As turmas do 1\%/3 e 1\%9 respectivamente, no dia da apresentação das atividades do projeto, na Escola Estadual Dr. Mariano da Rocha.

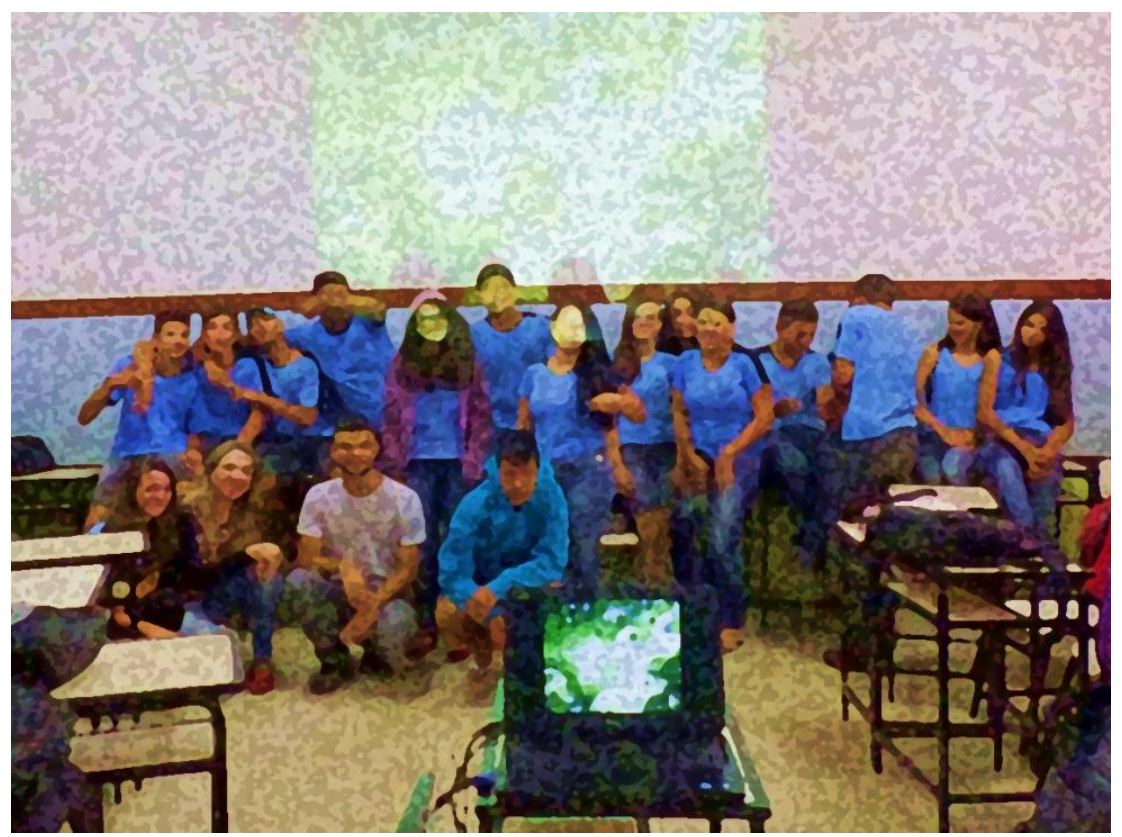

Fonte: Geosociobiodeversidade-PIBID-Geografia. Disponível em: http://pibidgeografiaufv.blogspot.com/2015/03/que-osjogos-comecem.html. Acesso em 29 jun. 2021.

No primeiro encontro, que intitulamos, Introdução à Geografia, foi destinado a responder a seguinte pergunta: o que a Geografia estuda? tendo em vista a grande diferença existente entre os conteúdos tidos como geográficos. Foram apresentados os autores responsáveis pela sistematização da ciência (Ritter e Humboldt) e o que estudavam, introduzindo o conceito de "espaço geográfico". 
No segundo encontro (Figuras 3 e 4), a preocupação foi abordar o substrato rochoso, onde se deteve atenção na explicação da dinâmica de formação das rochas, seus diferentes tipos e características. Como elas influenciam na paisagem atual e o entendimento de que algo aparentemente estático na verdade é dinâmico e está em constante transformação, mesmo que em um tempo diferente do tempo do homem.

Figura 3: Construção do quebra cabeças 3D dos movimentos de subducção e convergência das placas tectônicas.

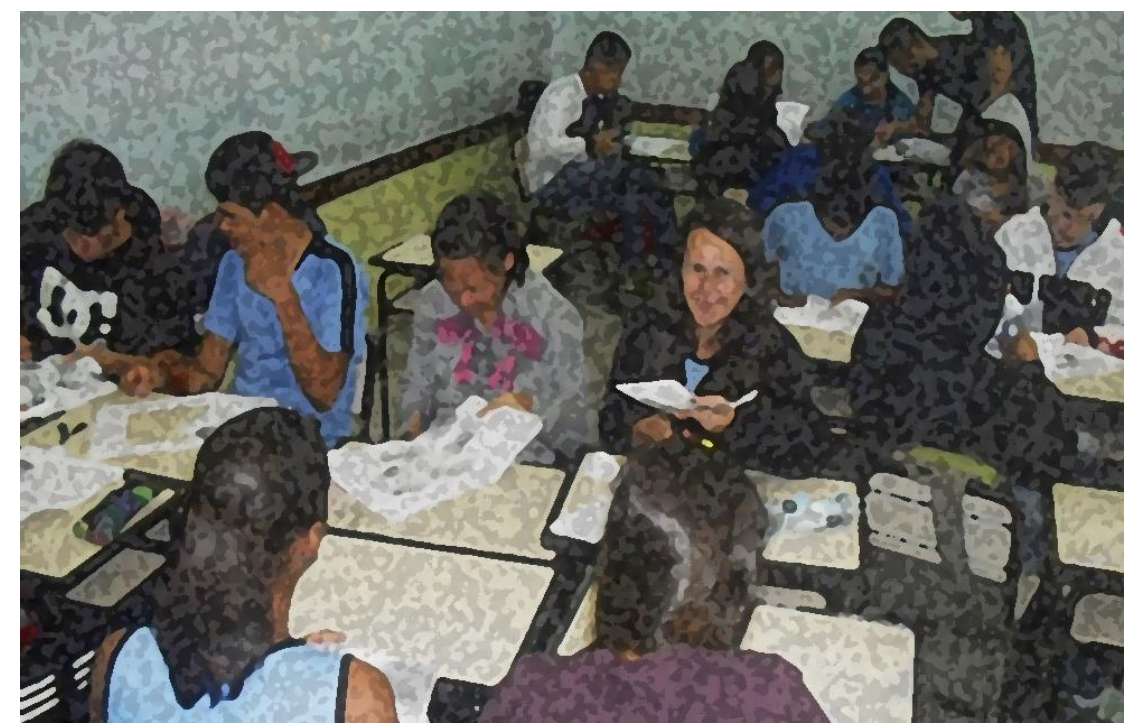

Fonte: Geosociobiodeversidade-PIBID-Geografia. Disponível em: http://pibidgeografiaufv.blogspot.com/2015/05/e-basede-tudo.html. Acesso em 30 jun. 2021.

Figura 4: Modelo final dos quebra cabeças ilustrados na figura anterior e produto dos trabalhos em sala de aula.

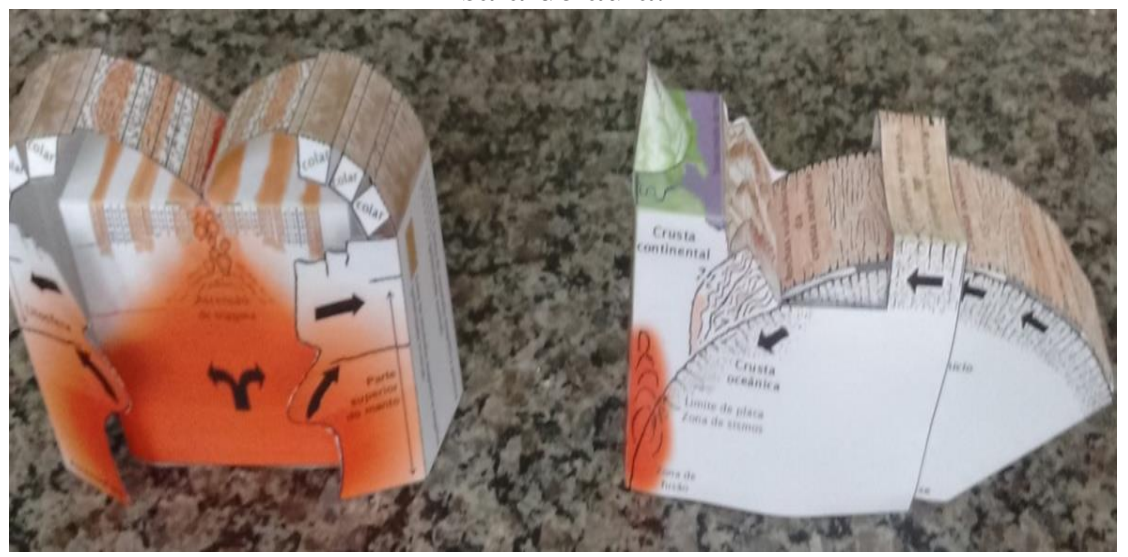

Fonte: Geosociobiodeversidade-PIBID-Geografia. Disponível em: http://pibidgeografiaufv.blogspot.com/2015/05/e-base-detudo.html Acesso em 30 jun. 2021.

No terceiro encontro, procurou trabalhar a questão da cartografia, solo, relevo e hidrologia. A cartografia é evocada para demonstrar que o "espaço geográfico" é dotado de acidentes, imperfeições. Solo e relevo condicionam de diversas maneiras a vida do homem na Terra que, por sua vez, depende 
dos cursos d'água formados na superfície do planeta. A técnica adotada para o envolvimento dos discentes foi a da maquete (Figura 5), onde a área retratada escolhida foi selecionada na carta topográfica de Teixeiras, onde foi possível identificar a localização da Escola, bem como a hidrografia do entorno da instituição de ensino.

Figura 5: Maquete do relevo referente aos arredores da escola em Teixeiras-MG.
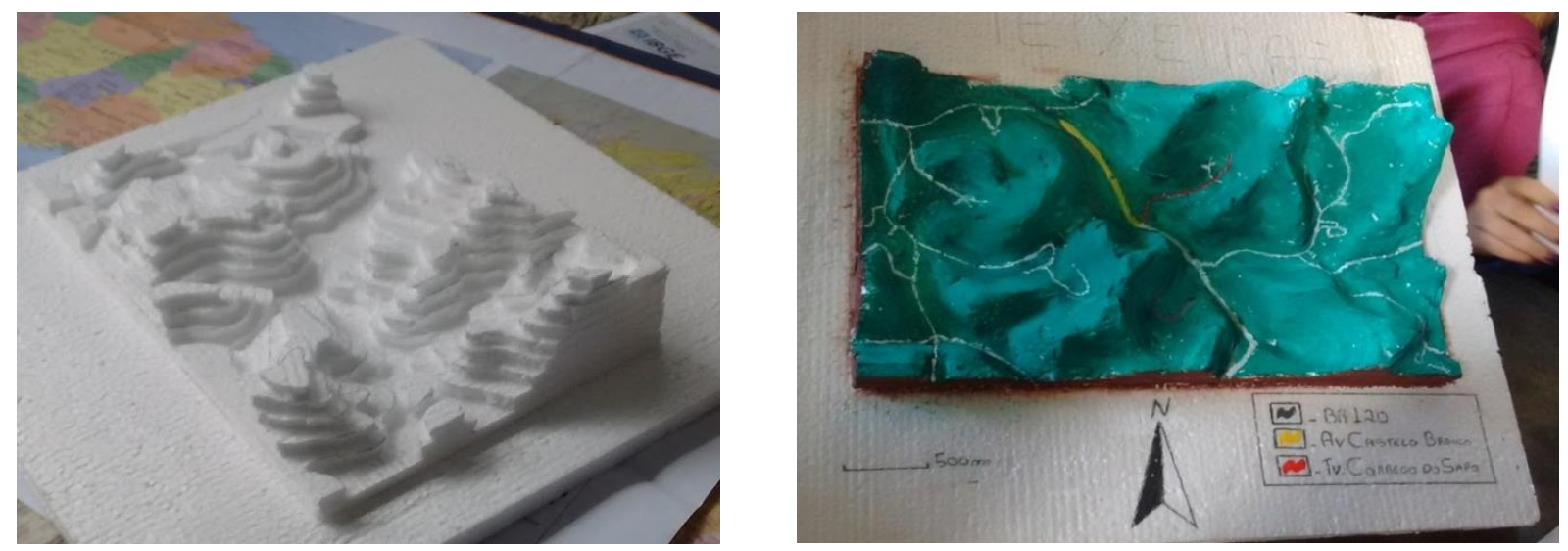

Fonte: Geosociobiodeversidade-PIBID-Geografia.Disponível em: <http://pibidgeografiaufv.blogspot.com/2015/08/neles-pisamos-epouco-os-conhecemos.html>. Acesso em 29 jun. 2021.

No quarto encontro, o tema abordado foi vegetação, clima e urbanização. Iniciou-se atemática, inicialmente, explorando o conceito de albedo (a capacidade que as coisas possuem de refletir na atmosfera o calor que chega até elas pelo sol) é eleito para promover a inter-relação entre o clima urbano, o crescimento das cidades e a necessidade de criação de áreas verdes, que influenciam no conforto térmico e na vida do homem.

Em termos geográficos, o albedo é a medida da quantidade de radiação solar refletida por um corpo ou uma superfície (AYOADE, 1996, p. 25), sendo calculado como a razão entre a quantidade de radiação refletida e a quantidade de radiação recebida. E os fatores que influenciam: a cor, a densidade e a umidade contida no objeto.

Os objetos mais escuros refletem menos a energia solar do que os de cores mais claras, que refletem mais. Materiais iguais com diferentes quantidades de umidade em seu interior impactam diretamente essa relação, como por exemplo, a areia da praia seca e molhada. $\mathrm{O}$ albedo maior na areia seca do que na molhada, que absorve a energia para produzir a evaporação da água, E em relação a densidade, pode-se citar o exemplo de paredes. As paredes mais grossas armazenam mais energia, e por conseguinte liberam a mesma energia após o pôr do sol, de maneira lenta, contribuindo para o aquecimento do ar no seu entorno imediato. Essas características, por sua vez, afetam diretamente, na produção de imagens produzidas por sensores orbitais instalados em satélites artificiais, que foram trabalhadas com os alunos (Figura 6). 
Figuras 6: $1 \%$ e 1\%, respectivamente da esquerda para a direita, incluindo as imagens utilizadas e a experiência relativa à cor e ao albedo.

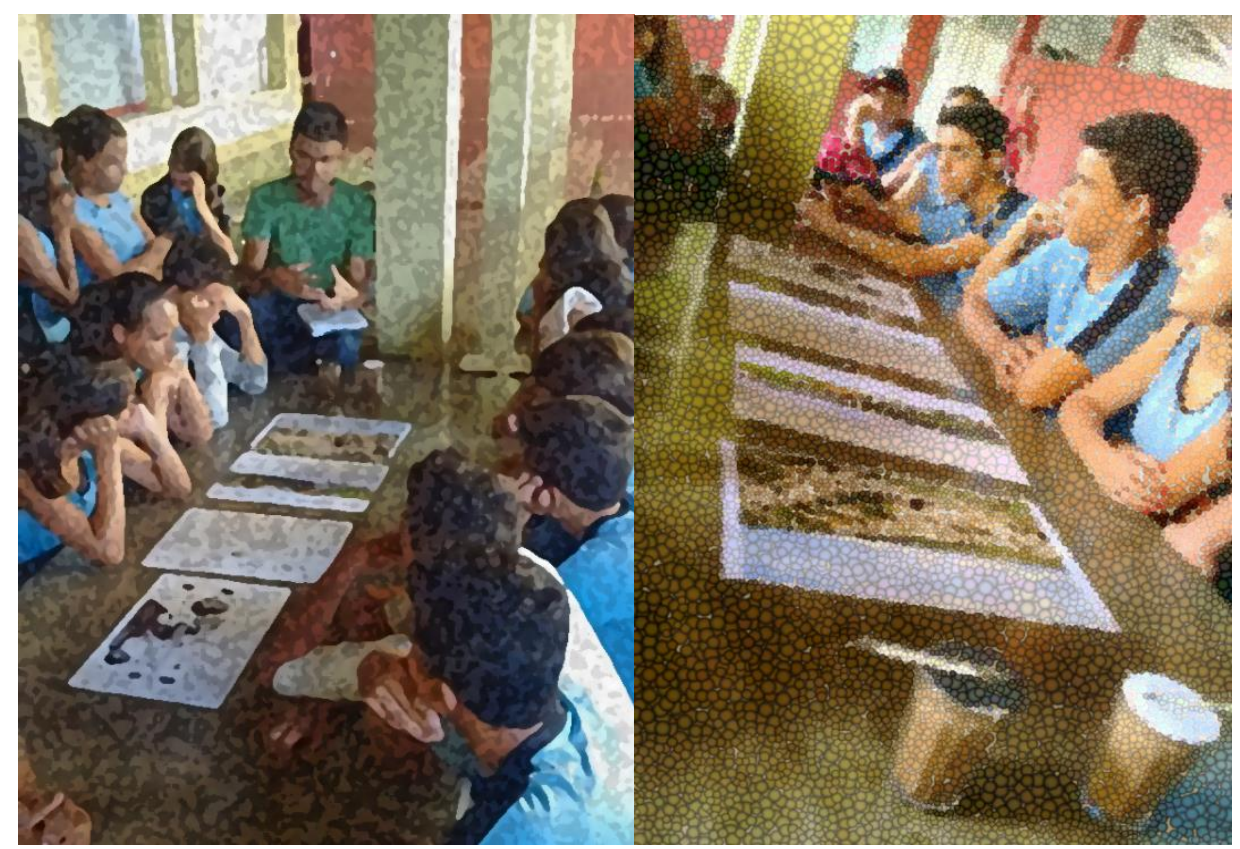

Fonte: Geosociobiodeversidade-PIBID-Geografia.Disponível em: <http://pibidgeografiaufv.blogspot.com/2015/11/nada-deroupas-pretas-no-verao-pessoal.html>. Acesso em 29 jun. 2021.

A resposta e interesse dos discentes foram acima das expectativas iniciais, pois os mesmos, sem apresentar uma consciência do conhecimento envolvido no processo de elaboração das cartas topográficas e imagens de satélites, conseguiram compreender e reconhecer os objetos, bem como a localização de equipamentos urbanos, além de conhecer o seu lugar, a partir de uma outra perspectiva.

Ao final das etapas do trabalho ao longo do primeiro semestre do ano de 2016, os produtos gráficos, blocos diagramas e interpretação de mapas cartográficos, as duas turmas envolvidas nas etapas do projeto, os alunos divididos em grupos apresentaram as atividades desenvolvidas propostas para a turma, no mesmo dia, onde foi possível registrar as turmas no pátio da escola para efeito de encerramento das atividades, os alunos do primeiro ano do Ensino Médio do turno da manhã no pátio da escola.

\section{REFLEXÕES SOBRE A TENTATIVA DE SUPERAÇÃO DE UMA GEOGRAFIA FRAGMENTADA}

O conflito ambiental é colocado na pauta do dia, nos fóruns políticos, sociais e educacionais. A ciência geográfica, no ambiente escolar, é a responsável por apresentar o mundo em sua complexidade aos alunos da Educação Básica, incorporando a relação da sociedade e a natureza. Mas, apesar deste esforço, a estrutura curricular e a grade de horários da escola é um elemento, importante, 
que nos ajuda a pensar o ensino de gavetas nos bancos escolares, que muitas das vezes, acarreta um deslocamento do mundo real, como também da articulação dos conteúdos sequenciais. Apesar da preocupação referente aos problemas ambientais, os conteúdos ligados aos elementos físicos naturais, compreendidos como parte integrante da Geografia Física, é de certa maneira apresentada de modo desvinculado das atividades humanas sobre a superfície terrestre.

Tal fato é observado por Vicente e Oliveira (2019) ao analisarem o entendimento e práticas dos professores de Geografia da Educação Básica, referentes à Geografia Física e os principais obstáculos que emperram o ensino das temáticas físico-naturais e as áreas de maior demanda de capacitação docente. As mesmas autoras constataram que os professores de Geografia pesquisados requerem uma capacitação docente em relação à área de Geografia Física e seu ensino, que vão ao encontro da discussão teórica da Geografia Física atual, buscando outras metodologias, além de novos recursos didáticos para se ensinar as temáticas físico-naturais, sobretudo nas áreas de Climatologia, Geologia e Geomorfologia.

Desse modo, a sua renovação acompanha as transformações sociais, econômicas, políticas e culturais do território. E neste sentido, a Geografia escolar é um instrumento para que o aluno entenda as contradições existentes na sociedade e no espaço. Com base nessas primícias, Mendonça (2019, p. 29) requalifica a Geografia Física e a coloca como articulada as ciências humanas, ou seja, incorporando a dimensão humana para o debate ambiental. Assim como afirma Petersen et al. (2014) ao dizer que a Geografia Física estuda os processos e as características de formação da Terra, bem como as atividades humanas que causam interferência no meio ambiente.

Em uma visão mais ampliada, conforme Oliveira (2015) aponta a necessidade do ensino de Geografia Física voltar-se para o conhecimento aprofundado da composição e dinâmica processual da natureza, bem como as derivações oriundas de sua apropriação e transformação pela sociedade, permitindo uma visão holística da realidade, olhando para os fatores, características e processos que influenciam o meio ambiente e como esses elementos interagem, assegurado uma correta análise do espaço, mantendo conforme Suerteregaray (2001) o princípio de uma Geografia una. Isto quer dizer que, quando pensamos em espaço geográfico, compreendemo-lo como conjugação de diferentes categorias, quais sejam: natureza, sociedade e espaço tempo (SUERTEREGARAY, 2002, p. 111). Nesse sentido, Casseti (2002) ao considerar o caráter ontológico de natureza:

[...] na qual a matéria sintetiza os fenômenos naturais e sociais, busca-se a compreensão da "unidade real" a como possível objeto de superação da relação dicotômica que legitima e reproduz o processo de alienação. A questão central fundamenta-se na necessidade de se despertar para uma nova forma de pensar o mundo, um novo paradigma, que implique na superação do estado de crise[...]. (CASSETI, 2002, p. 165). 
Porém, apesar do esforço de alguns pesquisadores em demonstrar a importância da Geografia Física, no ambiente escolar, há um segmento de profissionais do Ensino de Geografia, conforme Cavalcanti (2008), que reconhece a Geografia Escolar como campo de conhecimentos, que pode ter uma significativa contribuição ao processo de formação do aluno da Educação Básica e se constitui como aquela efetivamente ensinada na escola, o conhecimento geográfico trabalhado na sala de aula, e por isto, não é a Geografia acadêmica, mas, tem nela uma referência.

Dito isto, é possível dizer segundo Ascenção e Valadão (2017) e Cunha e Leite (2019), que entre os conteúdos com os quais a Geografia Escolar trabalha estão os componentes físico-naturais, relacionados aos processos físicos, às dinâmicas da natureza. Todavia, o processo formativo docente, ainda apresenta um distanciamento da preocupação, no que se refere ao tratamento didático e pedagógico, como constatado por Morais (2011). Neste contexto, os alunos formados do Ensino Médio, ao ingressarem, como por exemplo, em um curso de Geografia, podem retroalimentar o problema e potencializar uma visão distorcida do ensino da Geografia nas Escolas. Isso pode ser verificado nos estudos de Marinho (2020), que ao buscar compreender a noção de Natureza dos acadêmicos do curso de licenciatura em Geografia, na Universidade Federal de Viçosa, identificou três nuances. A primeira foi a Natureza intocada, seguida por uma Natureza transformada e uma Natureza enquanto recurso.

Essa avaliação demonstra como o ensino de Geografia na Escola, ainda não consegue superar a dicotomia estabelecida entre a sociedade e natureza, pois ao reconhecer três grupos de ideias relacionadas, isso demonstra uma incongruência, que se retroalimenta, quanto futuros licenciados buscam a formação universitária, aprofundando a dicotomia, que é mais aguda no meio universitário, onde a fragmentação do saber geográfico implodiu a Geografia, apesar das tentativas de elaboração de caminhos integrativos, conforme explorado por Oliveira e Montezuma (2011), por meio da História ambiental e a Geoecologia, ampliando os horizontes da Geografia Física.

Apesar de Figueró (2011, p. 39) dizer que caberá a Geografia Física impulsionar-se em direção ao um novo olhar sobre a natureza transfigurada, matizada de artefatos de uma sociedade cada vez mais urbanizada, cada vez mais necessitada da interação com a natureza. E por conta disso, Mendonça (2002 e 2011) destaca a necessidade da Geografia Física olhar o meio urbano como um locus de grande partes dos problemas socioambientais urbanos de grande complexidade, nãos exclusivamente nas grandes cidades, mas também em áreas urbanas de médio e pequeno porte.

Mas, apesar disso, a busca da compreensão do mundo real e a incorporação de novas ideias para a superação não apenas da dicotomia, mas de construção de uma nova forma de compreensão do mundo, deve ser capitaneada pela articulação e o diálogo entre as ciências, a fim de criar uma nova cidadania. 
Essa reflexão, tenta compreender jogar luz nos problemas relacionados aos métodos de ensino escolar, como este aplicado neste trabalho. Pois, apesar da sequência didática, fundamenta teoricamente ter gerado um interesse sobre a relação entre os indivíduos e seu lugar, principalmente, nas aulas de cartografia que foi elaborado uma maquete do ambiente do entorno da escola. A curiosidade ficou sobre as formas e não sobre as relações entre as formas físico naturais e os tipos de ocupações humanas na paisagem, muito embora o esforço de despertar o interesse por parte dos discentes.

Tal fato nos faz refletir na seguinte questão. Como suplantar a limitação do pensar, tanto na Escola, quanto no meio acadêmico da Geografia, a fim de gerar uma prática de conscientização cidadã? Talvez, tenhamos que elaborar novas formas de pensamento e raciocínio que supere as concepções rígidas por atitudes epistemológicas como integração, diálogo e contextualização (ÁGUILA, 2011, p. 163).

A simples participação dos alunos nas atividades didático-pedagógicas apresentadas não garante que tenham formado um pensamento crítico e reflexivo. Talvez, em algum momento, durante o desenvolvimento das atividades, possa de algum o modo ter pensado sobre as questões problematizadas. Entretanto, se esse momento foi alcançado, pois a semente da curiosidade foi dispersada. E como toda semente ao cair em solo fértil germina, espera-se que as mesmas possam encontrar alunos curiosos, que possam promover o crescimento da flor da vida, que necessita sempre de um ser humano consciente e capaz de prover as condições adequadas para sua manutenção. E assim, quem sabe que o esforço realizado no ambiente escolar, possa gerar uma mudança de hábito.

\section{CONSIDERAÇÕES FINAIS}

No magistério, o professor desenvolve uma atividade que não se encerra, está sempre submetida a uma série de acertos, erros e adaptações a estes erros. Promover momentos, durante a graduação, capazes de refletir sobre tais erros é o que engrandece os licenciandos em geral, sendo que o PIBID é um programa que vem se mostrando capaz de promover este momento de reflexão. Já os ideais geossistêmicos aplicados ao ensino revelam uma nova possibilidade de integração entre os conteúdos geográficos no Ensino Básico, contrários à atual compartimentação do conhecimento. A experiência aqui relatada é apenas o início, uma das muitas maneiras possíveis de associação entre a Geografia, a Educação Ambiental e o Geossistema.

A ciência geográfica possui um papel importante para com as questões ambientais em sala de aula e a Escola serve como campo de estudo e entendimento da sociedade/comunidade que a rodeia. Compreender a Escola e suas relações é o mesmo que desvendar parte dos mistérios que envolvem a 
comunidade escolar e, sobretudo, conseguir a possibilidade de atuação efetiva na mesma, seja de imediato ou em um futuro próximo. O entendimento do ser humano enquanto um elemento da natureza, capaz de promover transformações intensas na paisagem, é uma temática que deve ser trabalhada cada vez mais, a fim de se obter uma Escola (e por consequência uma comunidade escolar) consciente de sua "natureza" e de seu "meio ambiente".

Ao longo do percurso da aplicação da sequência didática empregada e apresentada neste trabalho, alcançou o objetivo proposto, na medida em que, os alunos se interessaram e participaram de maneira profícua, colocando suas questões e dúvidas, o que nos permiti inferir que a temática despertou interesse em razão da forma de apresentação e das estratégias didático-pedagógicas utilizadas.

\section{REFERÊNCIAS}

ÁGUILA, R. H. El papel de la Geografia Física em contexto del a educación ambiental y em laconstrucción de lasostenibilidad local. In: FIGUERÓ, A. S. e FOLETO, E. (orgs.).: Diálogos em Geografia Física. Santa Maria: EdUFSM, p. 158-190, 2011, 206p.

ANJOS, L. C. S.; COSTA, I. G. A contribuição do PIBID à formação docente. In:SEMINÁRIO DE SOCIALIZAÇÃO DO PIBID, 2, Anais..., Alfenas, UNIFAL - MG, 2012.

AYOADE, J. O. Introdução à climatologia para os trópicos. 4ed. Editora Bertrand: Rio de Janeiro, 1996, 332p.

BERTRAND, G. Paisagem e geografia física global: Esboço metodológico. Revista RA'E GA, Curitiba-PR, n. 8, p. 141-152, 2004. Disponível em: https://revistas.ufpr.br/raega/article/ view/3389/2718. Acesso em: 25 jun. 2021.

CALLAI, H. C. A Geografia e a escola: muda a geografia? Muda o ensino? Revista Terra Livre, São Paulo-SP, n. 16, p. 133-152, 12001.

CASSETI, V. A natureza e o espaço geográfico. In: MENDONÇA, F. KOZEL, S. (orgs.).: Elementos de Epistemologia da Geografia contemporânea. Curitiba: EdUFPR, p. 145-164, 2002, 265p.

CAVALCANTI, L. S. A Geografia escolar e a cidade: Ensaios de Geografia para a vida urbana cotidiana. Campinas, SP: Papirus, 2008

CUNHA, L. F. F.; LEITE, C. M. A abordagem dos componentes físico-naturais na geografia escolar. In: ENCONTRO NACIONAL DE PRÁTICA DE ENSINO EM GEOGRAFIA, 14, Anais..., Campinas: AGB, São Paulo-SP, 2019. Disponível em: https://ocs.ige.unicamp.br/ojs/anais14enpeg/ article/view/2905.Acesso em: 22 jan. 2021.

FERREIRA, A. B. H. Mini Aurélio Século XXI: o minidicionário da língua portuguesa. $4^{\mathrm{a}}$. ed. Rio de Janeiro: Nova Fronteira, 2001.

FIALHO, E. S. O meio ambiente: o discurso geográfico rumo a transdisciplinaridade. Revista Ponto de Vista, Viçosa-MG, v. 4, n. 1, p. 37-46, 2007. Disponível em: https://periodicos. ufv.br/RPV/article/view/9747. Acesso em: 2 dez. 2020. 
FIALHO, E. S. A geografia escolar e as questões ambientais. Revista Ponto de Vista, Viçosa-MG, v. 5, n. 1, p. 49-64, 2008. Disponível em: https://periodicos.ufv.br/RPV/article/view/9722. Acesso em: 2 fev. 2020.

FIALHO, E. S. As temáticas físicas e ambientais na Geografia Escolar. In: MAIA, D. C. (org.).: Ensino de Geografia em debate. p. 91-113, Salvador: EDUFBA, 2014. 125p. Disponível em: https://www.researchgate.net/publication/323268120_As_tematicas_fisicas_e_ambientais_na_Geografia_ Escolar/stats\#fullTextFileContent. Acesso em: 2 mar. 2021.

FIGUERÓ, A. S. Tradição e mudança em Geografia Física: Apontamentos para um diálogo interno. In: FIGUERÓ, A. S. e FOLETO, E. (orgs.).: Diálogos em Geografia Física. Santa Maria: EdUFSM, p. 17-43, 2011, 206p.

GEOSOCIOBIODIVERSIDADE-PIBID-GEOGRAFIA. Que os jogos comecem. Disponível em: http://pibidgeografiaufv.blogspot.com/2015/11/nada-de-roupas-pretas-no-verao-pessoal.html. Acesso em:29 jun. 2021.

GEOSOCIOBIODIVERSIDADE-PIBID-GEOGRAFIA. Neles Pisamos e pouco conhecemos. Disponível em: http://pibidgeografiaufv.blogspot.com/2015/08/neles-pisamos-e-pouco-os-conhecemos. html. Acesso em: 29 jun. 2021.

GEOSOCIOBIODIVERSIDADE-PIBID-GEOGRAFIA. É a base de tudo. Disponível em: http://pibidgeografiaufv.blogspot.com/2015/05/e-base-de-tudo.html. Acesso em: 30 jun. 2021.

GEOSOCIOBIODIVERSIDADE-PIBID-GEOGRAFIA. Nada de roupas pretas no verão pessoal. Disponível em: http://pibidgeografiaufv.blogspot.com/2015/11/nada-de-roupas-pretas-no-veraopessoal.html. Acesso em: 30 jun. 2021.

GERALDINE, C. F. G. O meio como ambiente: da emergência às críticas de um conceito. Ateliê Geográfico, Goiânia-GO, v. 8, n. 2, p. 198-220, 2014. Disponível em: https://www.revistas.ufg.br/ atelie/article/view/24425. Acesso em: 15 mai. 2021.

GONÇALVES, C. W. P. Os (des) caminhos do meio ambiente. $2^{\text {a }}$ ed., São Paulo: Contexto, 1990. $148 \mathrm{p}$.

KANASHIRO, C. S. Livro didático de Geografia: PNLD, materialidade e uso na sala de aula. 163f. Dissertação (Mestrado em Ciências da Comunicação). Faculdade de Filosofia, Letras e Ciências Humanas, Programa de Pós-graduação em Ciências da Comunicação, 2008. Disponível em: https:// www.teses.usp.br/teses/disponiveis/27/27154/tde-07052009-155915/pt-br.php. Acesso em: 27 jun. 2021.

LUCIANO, H. J.; MORAES, D. A. F.; MARTINS, N.; SANTOS, A. C. M. Vocação ou profissão? Representações do ser e fazer docente. In: CONGRESSO NACIONAL DE EDUCAÇÃO, 11, 2013, Curitiba-PR, Anais... Paraná, 2013. Disponível em: https://educere.bruc.com.br/CD2013/pdf/ 7228_6177.pdf. Acesso em:3fev. 2021.

MARINHO, M. Geografia Física no ensino superior: entendimentos preliminares do conceito e das relações com a natureza. Revista Ponto de Vista, Viçosa-MG, v. 9, n. 3, p. 39-56, 2020. Disponível em: https://periodicos.ufv.br/RPV/article/view/10801. Acesso em: 5mar. 2021.

MENDONÇA, F. Geografia e meio ambiente. 9a ed., $1^{a}$ reimpressão, São Paulo: Contexto, 2014. $80 \mathrm{p}$.

MENDONÇA, F. Geografia Socioambiental. Revista Terra Livre-AGB, São Paulo-SP, n. 16, p. 113-132, 2001.

MENDONÇA, F. Geografia socioambiental. In: MENDONÇA, F. KOZEL, S. (orgs.).: Elementos de Epistemologia da Geografia contemporânea. Curitiba: EdUFPR, p. 121-144, 2002, 265p.

MENDONÇA, F. Geografia, Geografia Física e Meio ambiente: uma reflexão à partir da problemática socioambiental urbana. Revista da ANPEGE-Associação de Pós-graduação em Geografia, Dourados- 
MS, v. 5, n. 5, p. 123-134, 2019. Disponível em: https://ojs.ufgd.edu.br/index.php/anpege/article/ view/6594/3594. Acesso em: 30 jun. 2021.

MENDONÇA, F. A Geografia (Física) brasileira e a cidade no início do século XXI: Algumas contingências e desafios. In: FIGUERÓ, A. S. e FOLETO, E. (orgs.).: Diálogos em Geografia Física. Santa Maria: EdUFSM, p. 45-58, 2011, 206p.

MONTEIRO, C A. F. Geossistemas: a história de uma procura. São Paulo, Contexto. 2001, 127p.

MORAIS, E. M. B. O ensino das temáticas físico-naturais na geografia escolar. 2011. 310f. Tese (Doutorado em Geografia Humana) - Faculdade de Filosofia, Letras e Ciências Humanas, Universidade de São Paulo, São Paulo, 2011. Disponível em: https://www.teses.usp.br/teses/disponiveis/8/8136/tde13062012-122111/pt-br.php. Acesso em: 28 jun. 2021.

NOFFS, A. N.; RODRIGUES, R. C. C. A formação docente: Pibid e o estágio supervisionado. Revista ECurriculum. São Paulo-SP. V. 14, n. 1, p. 357-374, 2016. Disponível: https://revistas.pucsp.br/index.php/ curriculum/article/view/26851/19384. Acesso em: 2 mar. 2021.

NOFFS, N. A. A Ação dos Professores: da formação à articulação profissional: Processos de formação inicial de professores em contextos colaborativos: docência e práticas educativas desenvolvidas em escolas públicas do Estado de São Paulo - PIBID-PUC/SP. São Paulo: Artgraph, 2013.

NÓVOA, A Professores imagens do futuro presente. Lisboa: EDUCA Instituto de Educação Universidade de Lisboa, 2009.

OLIVEIRA, R. R.; MONTEZUMA, R. C. M. História ambiental e Geoecologia: Caminhos integrativos na Geografia Física. In: FIGUERÓ, A. S. e FOLETO, E. (orgs.).: Diálogos em Geografia Física. Santa Maria: EdUFSM, p. 191-206, 2011, 206p.

OLIVEIRA, J. G. R. A geografia escolar e o papel da geografia física. Revista Anekumene, BogotáCOL, n. 9, p. 19-25, 2015. Disponível em: https://revistas.pedagogica.edu.co/index.php/anekumene/ article/view/12644/8904. Acesso em: 10 fev. 2021.

PIMENTA, S. G.; LIMA, M. S. L. Estágio e docência. 7. ed. São Paulo: Cortez, 2012.

PETERSEN, J. F.; SACK, D.; GABLER, R. E. Fundamentos de Geografia Física. São Paulo: Cengage Learning, 2014.

REHBEIN, M. O. Ensaios sobre o meio (ambiente):os significados de natureza por olhares geográficos. Revista Geografar, Curitiba-PR, v. 5, n. 1, p. 155-175, 2010. Disponível em: https://revistas. ufpr.br/geografar/article/view/17787>. Acesso em: 28 jun. 2021.

REIS JÚNIOR, D. F. C.; PEREZ FILHO, A. Esperando a teoria: do holismo geo-sistêmico aos geossistemas. SIMPÓSIO NACIONAL DE GEOMORFOLOGIA, GEOMORFOLOGIA TROPICAL E SUBTROPICAL: PROCESSOS, MÉTODOS E TÉCNICAS,6, Anais..., Goiânia, UFG, Goiás, 2006. Disponível: http://lsie.unb.br/ugb/sinageo/6/11/466.pdf. Acesso em: 29 jun. 2021.

ROQUE ASCENÇÃO, V. de O.; VALADÃO, R. C. Por uma geomorfologia socialmente significativa na geografia escolar: uma contribuição a partir de conceitos fundantes. Acta Geográfica, Roraima-RR, Edição Especial de Ensino de Geografia, p. 179-195, 2017. Disponível em: https://revista. ufrr.br/actageo/article/view/4780. Acesso em: 23 mar. 2021.

SILVEIRA, H. E. Mas, afinal: o que é iniciação à docência? Atos de pesquisa em educação, Blumenau, v. 10, n. 2, p. 354-368, 2015.

SUERTEGARAY, D. M. A. Espaço Geográfico uno e múltiplo. Scripta Nova, Barcelona-ESP, v. 5 , n. 93, 2001. Disponível em: https://revistes.ub.edu/index.php/ScriptaNova/article/view/313. Acesso em 3 fev. 2021. 
SUERTEGARAY, D. M. A. Geografia Física (?) Geografia Ambiental (?) ou Geografia e Ambiente (?). In: MENDONÇA, F. KOZEL, S. (orgs.).: Elementos de Epistemologia da Geografia contemporânea. Curitiba: EdUFPR, p. 111-144, 2002, 265p.

VICENTE, K. C.; OLIVEIRA, J. G. R Entendimento e práticas pedagógicas dos professores de Geografia relativos à Geografia Física. Revista Geografia em Atos, Presidente Prudente-SP, n. 14, v. 7, p. 8-27, 2019. Disponível em: https://revista.fct.unesp.br/index.php/geografiaematos/article/ view/6093. Acesso em 24 abr. 2021. 